\title{
Scenario of molar pregnancy in a tertiary care centre in Delhi, India
}

\author{
Seema Pundir, Vinita Gupta, Sonal Prasad*
}

Department of Obstetrics and Gynecology, Dr. Baba Saheb Ambedkar Medical College and Hospital, New Delhi, India

Received: 15 July 2019

Accepted: 30 August 2019

*Correspondence:

Dr. Sonal Prasad,

E-mail: sonal.pras@gmail.com

Copyright: () the author(s), publisher and licensee Medip Academy. This is an open-access article distributed under the terms of the Creative Commons Attribution Non-Commercial License, which permits unrestricted non-commercial use, distribution, and reproduction in any medium, provided the original work is properly cited.

\begin{abstract}
Background: Molar pregnancies represent a significant burden of disease on the spectrum of gestational trophoblastic diseases with incidence varying with geographic region. Aim was to review all molar pregnancies admitted at our institution and to study the incidence, clinical presentation, management, complications and outcome of molar pregnancies.

Methods: An observational study was done in department of obstetrics and gynaecology at Dr. BSA Medical College and Hospital among women with molar pregnancy over two years.

Results: The incidence of molar pregnancy of the institute was 1.05/1000 deliveries. 21- 25 years age group and nulliparous women constituted $28.1 \%$ of patients. Amenorrhea $(100.0 \%)$ was the commonest presenting complaints followed by abnormal vaginal bleeding $(90.62 \%)$. Anemia $(37 \%)$ was the commonest complication followed by acute hemorrhage $(31 \%)$ and hyperthyroidism (18\%). Suction evacuation was done in $96.8 \%$ of patients and $87.5 \%$ required blood transfusion. Only $6.2 \%$ (2/32) of patients had post evacuation chemotherapy. None of the cases developed choriocarcinoma. Limitation of the study was that the incidence of subsequent pregnancies after complete treatment of molar pregnancies was not studied.

Conclusions: Early diagnosis of complete molar pregnancy can change the clinical presentation, diagnosis, and treatment of molar pregnancy. There is need for early recognition, timely referral, prompt and proper treatment of this condition. Adequate follow-up of the patients and need for contraception should be reinforced.
\end{abstract}

Keywords: Gestational trophoblastic diseases, H mole, India, Molar pregnancy, Suction evacuation, Vaginal bleeding

\section{INTRODUCTION}

Hydatidiform mole (H-mole) refers to an abnormal pregnancy characterized by varying degrees of trophoblastic proliferation (both cytotrophoblast and syncytiotrophoblast) and vesicular swelling of placental villi associated with an absent or an abnormal fetus/embryo. Reports of the incidence of molar pregnancy vary by geographic region. The highest incidence of hydatidiform mole per 1000 pregnancies is seen in South East Asia with rates ranging from 13 in
Indonesia, 8 in Taiwan, 5 in Philippines and 3.8 in Japan, North America, Europe and Oceania have the lowest incidence with approximately 0.5-1.84/1000 pregnancies. ${ }^{1-3}$ Molar pregnancies represent a significant burden of disease on the spectrum of gestational trophoblastic diseases.

The aim of the study was to review all molar pregnancies admitted at the institution and to study the incidence, clinical presentation, management, complications and outcome of molar pregnancies. 


\section{METHODS}

After approval of institutional ethical review committee, a single centred observational study was done at Dr Baba Saheb Ambedkar medical college and Hospital, Delhi from $1^{\text {st }}$ April 2017 to $31^{\text {st }}$ March 2019. All patients between 16-40 years of age with diagnosed molar pregnancy seeking treatment at our institute were included in the study. Patients who had malabsorption syndrome, history of choriocarcinoma or Beta hCG secreting tumors like ovarian germ cell tumors were excluded from the study.

Data abstracted included patient's age, parity, presenting symptoms, gestational age at diagnosis, uterine size, ultrasonographic findings, serum TSH Levels, BhCG level at the time of diagnosis and at follow-up after evacuation, and blood loss during evacuation.

All patients were admitted after diagnosis, and 2 units of packed RBC were cross-matched. Under general anaesthesia suction evacuation was performed. BhCG with a radioimmunoassay sensitivity of $5 \mathrm{mIU} / \mathrm{mL}$ was used. Following evacuation, BhCG levels for all the patients were obtained. Patients were followed weekly in the clinic until 3 consecutive normal BhCG levels one week apart were achieved. Following the normalization of BhCG, patients were followed by monthly BhCG for 6 months. All patients were counselled to use contraceptive to prevent pregnancy during the period of follow up.

Data was entered and analyzed using Excel 2000 (Microsoft Corporation, Seattle, WA, USA).

Statistical analysis included calculation of mean and standard deviation for continuous variables, and frequency distribution for categorical variables.

\section{RESULTS}

A total of 29,532 deliveries were recorded from 1st April 2017 to 31st March 2019with 32 diagnosed molar pregnancies. The incidence of molar pregnancy of the institute was 1.05/1000 deliveries. Out of these 32 cases, 24 were complete mole, 7 had partial mole and 1 had invasive mole. The Demographic parameters of patients are summarised in Table 1.

The mean age of the patients was 31.3 (8.7) years. BMI was $27.3 \pm 12.9$ and the mean gestational age was 14.8 \pm 8.3.Majority $(28.1 \%)$ of patients were of the $21-25$ years age group.

The clinical manifestations of the patients are shown in Figure 1. Only one patient had a history of 2 consecutive molar pregnancies. Amenorrhea (100.0\%) was the commonest presenting complaints followed by abnormal vaginal bleeding $(90.62 \%)$. Large for gestational age $(50 \%)$ and hyperemesis gravidarum $(43.5 \%)$ were also common presenting clinical features.
Table 1: Demographic distribution of patients with molar pregnancy.

\begin{tabular}{|c|c|c|c|}
\hline \multicolumn{2}{|c|}{$\begin{array}{l}\text { Demographic } \\
\text { parameters }\end{array}$} & $\begin{array}{l}\text { Number } \\
\text { of patients }\end{array}$ & Percentage \\
\hline \multirow{7}{*}{$\begin{array}{l}\text { Age in } \\
\text { years }\end{array}$} & $16-20$ & 2 & 6.2 \\
\hline & $21-25$ & 9 & 28.1 \\
\hline & $26-30$ & 6 & 18.7 \\
\hline & $31-35$ & 5 & 15.6 \\
\hline & $36-40$ & 4 & 12.5 \\
\hline & $41-45$ & 4 & 12.5 \\
\hline & $46-50$ & 2 & 6.2 \\
\hline \multirow{6}{*}{ Parity } & 0 & 9 & 28.1 \\
\hline & 1 & 5 & 15.6 \\
\hline & 2 & 6 & 18.7 \\
\hline & 3 & 2 & 6.2 \\
\hline & 4 & 4 & 12.5 \\
\hline & $\geq 5$ & 6 & 18.7 \\
\hline
\end{tabular}

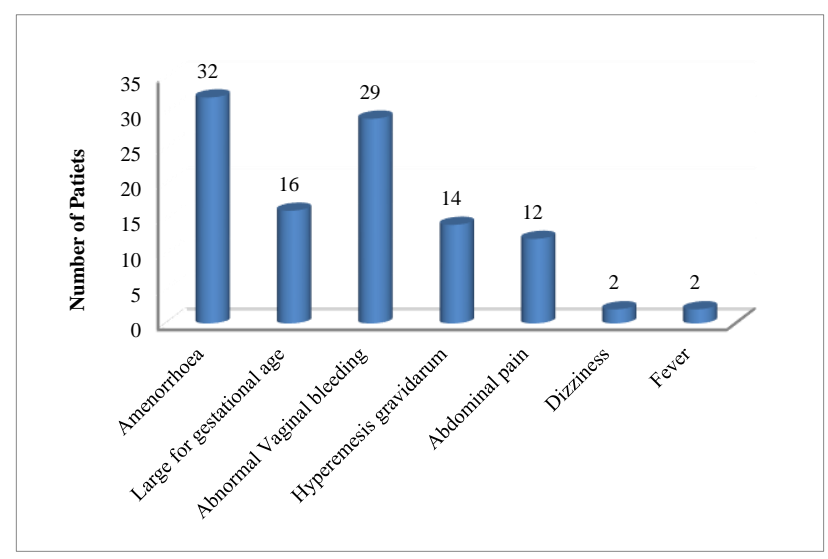

Figure 1: Bar Diagram showing clinical features of patients presenting with $\mathrm{H}$ Mole.

Among all the patients, $100.0 \%$ (32/32) tested positive to pregnancy test. Twenty-nine of the $32(90.62 \%)$ patients were diagnosed by pelvic ultrasonography. The typical snow-storm appearance was described in 56.25\% (18/32) of total cases. Ovarian enlargement by theca-lutin cyst was seen in 3 patients $(9.37 \%)$.

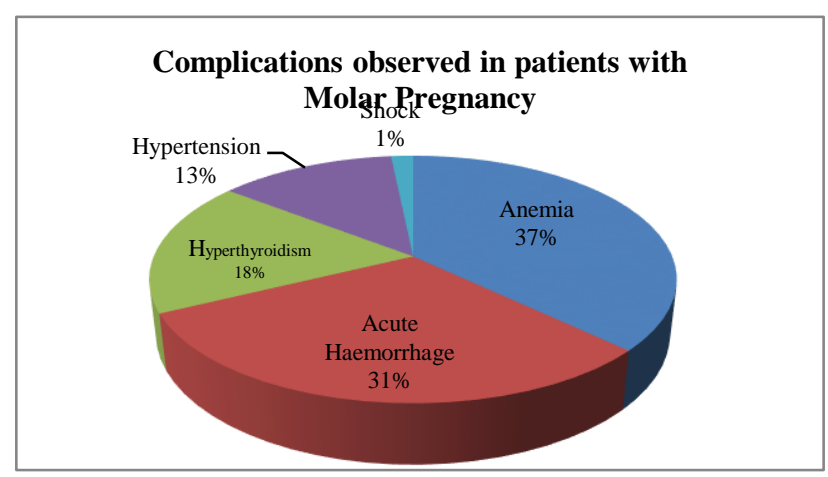

Figure 2: Pie chart depicting the complications observed in patients with molar pregnancy. 
Figure 2 shows the complications observed in patients with molar pregnancy. Anemia (37\%) was the commonest complication followed by acute hemorrhage $(31 \%)$ and hyperthyroidism $(18 \%) .1 \%$ of the patients presented with shock.

Suction evacuation was done in thirty one out of the thirty two cases $(96.8 \%)$ and only one $(3.1 \%)$ patient had hysterectomy for uncontrollable hemorrhage following suction evacuation. Majority, $28(87.5 \%)$ had blood transfusion. Only $6.2 \%(2 / 32)$ of patients had post evacuation chemotherapy. None of the cases developed choriocarcinoma. The duration of follow up is summarised in Table 2.

Table 2: Summarising the duration of follow up of patients of $\mathrm{H}$ Mole.

\begin{tabular}{|lll|}
\hline Duration of Follow up & Frequency & Percentage \\
\hline 0-1 month & 7 & $21.8 \%$ \\
\hline 2-5 month & 13 & $40.6 \%$ \\
\hline 6 months- 1 year & 3 & $9.3 \%$ \\
\hline > 1year & 2 & $6.2 \%$ \\
\hline Loss to follow up & 3 & $9.3 \%$ \\
\hline
\end{tabular}

Time required obtaining normal BhCG values following evacuation was $69 \pm 6$ days. $28 \quad(87.5 \%)$ used contraception after receiving their treatment for the molar pregnancies. Barrier method using male condom was the most common contraceptive method used in $46.8 \%$ $(15 / 32)$ of cases.

\section{DISCUSSION}

In the study, the incidence of molar pregnancy was found to be $1.05 \%$. This figure is higher than $0.09 \%$ in Uganda, $0.16 \%$ in Japan, and $0.2 \%$ in Nigeria. ${ }^{4-6}$ The increased high incidence of molar pregnancy in the center may be due to the status of the teaching hospital as a referral center from various clinics both private and public. The highest incidence of hydatidiform mole per 1000 pregnancies is seen in South East Asia with rates ranging from 13 in Indonesia, 8 in Taiwan, 5 in Philippines and 3.8 in Japan.

Only $6.2 \%$ of patients of $\mathrm{H}$ mole in our study were of 16 20 years age group. Maximum incidence of $\mathrm{H}$ mole was found in 20-25 years age group (28.1\%) and in nulliparous women $(28.1 \%)$. It is disheartening because these young nulliparous women were just beginning their reproductive life.

The study has shown that more than $70 \%$ of the patients were in their 1 st trimester of pregnancy at the time of diagnosis. Also, the mean gestation age of the patients was $14.8 \pm 8.3$ weeks. This data is similar to the result of previous studies and documentations in the literature. ${ }^{7,8}$ This reflects the fact that there is need for early ultrasound examination in all pregnancies.
In addition, there should be an evaluation of all patients with history of amenorrhea, since with routine first trimester ultrasonography, a significant proportion of patients has been identified, even though they may be asymptomatic at the time of diagnosis. ${ }^{5}$

Besides amenorrhea, the study revealed that the most common clinical manifestation of molar pregnancy is abnormal vaginal bleeding. This occurred in more than $90 \%$ of cases. This agrees with documentations in the literature where more than $90 \%$ of patients with molar pregnancies presented with abnormal uterine bleeding, usually during the first trimester. ${ }^{7,9}$

Regarding the complications associated with molar pregnancies, this study had demonstrated that anemia (37\%) was the commonest complication, followed by, acute hemorrhage, and hyperthyroidism. These findings differ from a study in Nigeria where acute hemorrhage was the most common complication. ${ }^{10}$ Anemia and acute haemorrhage could also explain why almost all the patients $(87.5 \%)$ in the study received blood transfusion.

Approximately $13 \%$ of the studied patients had pre eclampsia. This agrees with findings of other studies. ${ }^{6,7}$ In explaining this, Aghajanian observed that pre eclampsia in the first trimester or early second trimester - an unusual finding in normal pregnancy - is pathognomonic for hydatidiform mole. ${ }^{7}$

Hyperthyroidism was detected in about $18 \%$ of cases. This could arise from stimulation of thyrotropin receptors by hCG. ${ }^{5,11}$ Hyperthyroidism occurring in patients with molar pregnancies is usually subclinical, and most patients remain asymptomatic. This rather high incidence of hyperthyroidism detected in the study suggested that a comprehensive pre-treatment hormonal evaluation should be conducted in molar pregnancy cases to prevent serious complications such as thyroid storm that could arise in these patients.

Suction evacuation was done in more than $90 \%$ of cases, and $6.2 \%$ of patient received post evacuation chemotherapy. This finding disagrees with reports of others. ${ }^{6}$ However, it is controversial whether prophylactic chemotherapy following complete molar pregnancy should be offered to all patients, even though studies have shown that the incidence of post molar gestational trophoblastic disease may be decreased with prophylactic chemotherapy. ${ }^{7}$ Therefore, it is not appropriate to give all patients routine prophylactic chemotherapy. ${ }^{12}$ In the case, post evacuation chemotherapy was given to only 2 patients who had post evacuation heavy vaginal bleeding. Prophylactic chemotherapy is also known to be useful in high risk group of women as it prevents metastasis and reduces morbidity. The other indications for prophylactic chemotherapy in hydatidiform mole include failure of beta hCG becoming normal by the stipulated time of 10-12 weeks, re-elevation of beta hCG post evacuation, and evidence of metastases irrespective of the level of beta hCG. ${ }^{12}$ 
It is noteworthy that the majority of the patients $(87.5 \%)$ accepted post evacuation contraception, and barrier contraceptives $(46.8 \%)$ were the most common contraceptive method used by the patients. These findings are similar to those presented in other studies. ${ }^{7,8,10}$ Following evacuation of the uterus, the use of contraceptive is recommended so that pregnancy is avoided for 12 months to minimize any deleterious effects on the developing oocytes and to minimize the confusion over disease relapse from hCG produced in pregnancy. ${ }^{5,11}$

One of the limitations of the study is that the incidence of subsequent pregnancies after complete treatment of molar pregnancies was not studied.

\section{CONCLUSION}

Hydatidiform mole remains an important cause of maternal morbidity. Early diagnosis of complete molar pregnancy can change the clinical presentation, diagnosis, and treatment of this disease. Even with the current widespread use of first trimester ultrasound, the dramatic presentation of complete mole is not very uncommon in the India. There is need for early recognition, timely referral, prompt and proper treatment of this condition. Adequate follow-up of the patients and need for contraception should be reinforced.

Funding: No funding sources

Conflict of interest: None declared

Ethical approval: The study was approved by the Institutional Ethics Committee

\section{REFERENCES}

1. Lurain I, John R. Gestational trophoblastic disease: epidemiology, pathology, clinical presentation and diagnosis of gestational trophoblastic disease, and management of hydatidiform mole. Am J Obstet Gynecol. 2010;203(6):531-9.

2. Newlands ES, Paradinas FJ, Fisher RA. Recent advances in gestational trophoblastic disease. Hematol Oncol Clin North Am. 1999;13:225.
3. Bracken MB, Brinton LA, Hayashi K. Epidemiology of hydatidiform mole and choriocarcinoma. Epidemiol Rev. 1984;6:52-75.

4. Kaye DK. Gestational trophoblastic disease following complete hydatidiform mole in mulago hospital, Kampala, Uganda. Afr Health Sci. 2002;2:47-51.

5. Agboola A. Trophoblastic tumours. Textbook of Obstetrics and Gynaecology for Medical Students. 2nd ed. Ibadan: Heinemann Educational Books (Nigerian) Plc. 2006:218-224.

6. Eniola OA, Mabayoje P, Ogunniyi SO. Hydatidiform mole in Ile-Ife, Nigeria: A 10 year review. J Obstet Gynaecol. 2001;21:405-7.

7. Aghajanian P. Gestational trophoblastic disease. In: Decherney AH, Nathan L, Goodwin TM, Laufer N, editors. Current Diagnosis Treatment in Obstetrics and Gynaecology 10th ed. New York: Mc Craw Hill Medical Publishing Division. 2007:885-895.

8. Srangsriwong S. Molar pregnancy in sappasithiprasong hospital. Med J Ubon Hosp. 1995;16:187-94.

9. Savage P, Seckl M. Trophoblastic Disease. In: Edmond KD, editor. Dewhurst's Textbook of Obstetrics and Gynaecology. 7th ed. UK: Black Well Publishing, Inc. 2007:117-124.

10. Obiechina NJ, Udigwe GO, Obi RA. Molar pregnancy: A ten year review at onitsha, Nigeria. J Med Invest Pract. 2001;3:26-31.

11. Fernando RJ, Williams AA, Adams EJ. Royal College of Obstetricians and Gynaecologists. The management of third and fourth degree perineal tears. RCOG Green top Guidelines No 29. 2007.

12. Dutta DC. Haemorrhage in early pregnancy. In: Konar H, editor. DC Dutta's Textbook of Obstetrics and Gynaecology. $7^{\text {th }}$ ed. London: New Central Book Agency P Ltd. 2011:158-199.

Cite this article as: Pundir S, Gupta V, Prasad S. Scenario of molar pregnancy in a tertiary care centre in Delhi, India. Int J Reprod Contracept Obstet Gynecol 2019;8:3981-4. 